\title{
High crystallinity polyethylene obtained in biphasic polymerization using pyridinium chloroaluminate ionic liquid
}

\author{
Wioletta Ochędzan-Siodłak • Katarzyna Dziubek • \\ Krystyna Czaja $\cdot$ Stanisław Rabiej $\cdot$ Roman Szatanik
}

Received: 6 May 2014 / Accepted: 8 August 2014 / Published online: 20 August 2014

(C) The Author(s) 2014. This article is published with open access at Springerlink.com

\begin{abstract}
A series of $N$ - $n$-alkylpyridinium chloroaluminate ionic liquids $\left[\mathrm{C}_{n}\right.$-py] $\left[\mathrm{AlCl}_{4}\right]$ (where $n$-alkyl $=n$-butyl, $n$-hex$\mathrm{yl}$, and $n$-octyl) was applied as a medium of the $\mathrm{Cp}_{2} \mathrm{TiCl}_{2}$ catalyst, activated by $\mathrm{AlEtCl}_{2}$ or $\mathrm{AlEt}_{2} \mathrm{Cl}$, to evaluate the influence of the studied ionic liquids on the performance of the biphasic ionic liquid/hexane ethylene polymerization and the properties of the produced polyethylene (PE). The best results were obtained using $N$ - $n$-butylpyridinium chloroaluminate. The polyethylene obtained in the biphasic polymerization have the high crystallinity, which was confirmed by DSC, WAXS and PALS methods, as well as the bulk density comparable to commercial HDPE. These unique properties results from the biphasic mode of the ethylene polymerization where the ionic liquid is used to immobilize the catalyst, and polyethylene is produced in the ionic liquids phase.
\end{abstract}

Keywords Polyethylene $\cdot$ Biphasic process $\cdot$ Ionic liquid · Metallocene catalyst

Electronic supplementary material The online version of this article (doi:10.1007/s10965-014-0558-5) contains supplementary material, which is available to authorized users.

W. Ochędzan-Siodłak $(\bowtie) \cdot K$. Dziubek $\cdot$ K. Czaja Department of Chemical Technology and Polymer Chemistry, Faculty of Chemistry, Opole University, Oleska 48, 45-052 Opole, Poland

e-mail: wioletta.siodlak@uni.opole.pl

S. Rabiej

Institute of Textile Engineering and Polymer Materials, University of Bielsko-Biala, Willowa 2, 43-309 Bielsko-Biala, Poland

R. Szatanik Institute of Physics, University of Opole, Oleska 48, 45-052 Opole, Poland

\section{Introduction}

Conventional polyolefins, such as polyethylene and polypropylene, constitute one of the most highly consumed thermoplastics in the world because of their good mechanical properties, chemical inertness, and low cost of production $[1,2]$. The significant need for these synthetic polymers, also for special applications, promotes the search for innovative olefin-based polymers with improved properties. Recent trends in polymer chemistry focus on new methods of control of polymer architecture, in order to improve their physicochemical properties. This can be achieved, for example, by controlling polyreaction conditions $[3,4]$.

The promising method, which allows to obtain tailor-make polyolefins, is application of biphasic liquid-liquid system in polymerization reaction. In such system, ionic liquids can be successfully used as one of two phases, due to good solubility of transition metal compounds. In contrast, poor miscibility of produced polyolefins allows separate them easily from reaction mixture. This allows for multiple reuse of the ionic liquid phase containing the catalyst. The waste of the expensive transition metal compound can be minimized and the polymerization yield can be improved. Moreover, kind of the applied ionic liquid has considerable influence on performance of the polymerization reaction $[5,6]$.

In this study, we focused on the biphasic polymerization of ethylene carried out using chloroaluminate $N$ - $n$-alkylopyridinium ionic liquids, where $n$-alkyl was $n$-butyl, $n$-hexyl or $n$-octyl, as media for the metallocene catalyst $\left(\mathrm{Cp}_{2} \mathrm{TiCl}_{2}\right)$ as well as the activator $\left(\mathrm{AlEt}_{2} \mathrm{Cl}\right.$ or $\left.\mathrm{AlEtCl}_{2}\right)$. These ionic liquids have not been investigated to date in the biphasic polymerization of olefins. It is noteworthy that this important group of the ionic liquids is characterized by their lower cost and greater thermal stability than the imidazolium analogues [7-11].

In order to better understand polymerization process, the properties of the polyethylenes such as: molecular weight, 
molecular weight distribution, branching, melting temperature, crystallinity, and bulk density were investigated. Particular attention was devoted to the determination of the structural analysis and crystallinity degree of PE obtained, that affect the application of the polymer. To determine these parameters Differential Scanning Calorimetry (DSC), WideAngle X-ray Diffraction (WAXS), and Positron Annihilation Lifetime Spectroscopy (PALS) were applied. In the structural analysis, the chosen technique can have considerable influence on the results obtained. DSC is quick and convenient method, thus it is commonly applied for determination of the crystallinity degree of polymers. WAXS also gives percentage crystallinity, and additionally, it offers opportunity to measure lamellae thickness $[12,13]$. Existence of sub-nanometer local free volume holes in amorphous polymer materials, which arises from their structural disorder, is another important element of polymer microstructure. During the past three decades PALS has developed to be the most important experimental method for studying subnanometer-size holes in polymers, and unique tool for microstructural analysis of polymeric systems [14-17].

\section{Experimental}

\section{Materials}

Ethylene (Linde AG Gaz) and pure nitrogen (Polgaz) were used after having been passed through a column of sodium metal supported on $\mathrm{Al}_{2} \mathrm{O}_{3}$. Pure-grade hexane ( $\mathrm{POCH}$, Gliwice) was refined with sulphuric acid, sodium hydroxide, distilled to gain a fraction $\left(62-67^{\circ} \mathrm{C}\right)$ and distilled again over sodium/benzophenone, and stored over sodium metal. Bis(cyclopentadienyl)titanium(IV) dichloride $-\mathrm{Cp}_{2} \mathrm{TiCl}_{2}$, ethylaluminium dichloride - $\mathrm{AlEtCl}_{2}$, and diethylaluminium chloride $-\mathrm{AlEt}_{2} \mathrm{Cl}$ (1 $\mathrm{M}$ as hexane solution), were applied as purchased. 1,2,4-Trichlorobenzene - TCB (99 wt.\%) (Aldrich) was purified by distillation.

\section{Measurements}

The FTIR analysis was accomplished by using a Nicole Nexus 2002 FT-IR spectrometer. The number of branches in the polyethylene samples was estimated by FT-IR analysis on the basis of the ratio of the band at 1,379.3 to the band at $1,368.7 \mathrm{~cm}^{-1}$. The samples were used in form of the polymer powder pills with $\mathrm{KBr}$. The former band results mainly from the presence of terminal methyl groups on the branches. The latter is the band of absorption of the methylene groups.

The NMR spectra were recorded on a Bruker Ultrashield spectrometer $(400 \mathrm{MHz})$. The linearity of the polyethylene was analyzed using ${ }^{13} \mathrm{C}$ NMR spectra (o-dichlorobenzene- $d_{4}$ solvent). The number of branches of the selected polyethylene samples was also confirmed by ${ }^{1} \mathrm{H}$ NMR (o-dichlorobenzene$d_{4}$ solvent) on the basis of the ratio of integrals of signal of the methyl groups (1.16 ppm) to methylene groups (1.55 ppm).

The molecular weight and molecular weight distribution of each polymer sample in the powder form were determined by gel permeation chromatography (Waters Alliance GPCV 2000) using 1,2,4-trichlorobenzene as the solvent at $142{ }^{\circ} \mathrm{C}$. The data was analyzed using polystyrene calibration curves.

The crystallinity and the melting temperature of the polyethylene in the powder form were estimated with a DSC 2010 TA Instruments. The samples were analyzed under nitrogen atmosphere, according to the following cycles: in the first cycle the sample was heated from 20 to $160{ }^{\circ} \mathrm{C}$, at a heating rate of $10{ }^{\circ} \mathrm{C} / \mathrm{min}$., leaving the material at $160{ }^{\circ} \mathrm{C}$ for $2 \mathrm{~min}$; the second cycle was done using a cooling rate of $10^{\circ} \mathrm{C} / \mathrm{min}$., until $20^{\circ} \mathrm{C}$; in the third cycle the sample was heated from 20 to $160{ }^{\circ} \mathrm{C}$, at a heating rate of $10^{\circ} \mathrm{C} / \mathrm{min}$. The melting temperature $\left(T_{m}\right)$ and the degree of crystallinity $(C)$ of the PE were obtained considering the second heating curves. The polymer crystallinity was calculated using the equation: $C=$ $\left(\Delta H_{f} / \Delta H_{t, c}\right) \times 100 \%$ where; $\Delta H_{f}$ - heat of fusion of the polyethylene sample, $\Delta H_{t, c}$ - heat of fusion of standard = $290 \mathrm{~J} / \mathrm{g}, C$ - crystallinity, \% [18-20]

The bulk densities were measured according to ASTM Standard D 1895.

X-ray diffraction of the polyethylene in the powder form were performed using a URD6 Seifert (Germany) diffractometer with a copper target X-ray tube $(\lambda=0.154 \mathrm{~nm})$ operated at $40 \mathrm{kV}$ and $30 \mathrm{~mA}$. $\mathrm{Cu} \mathrm{K} \alpha$ radiation was monochromised with a crystal monochromator. WAXS curves were recorded in the $2 \theta$ range $4-60^{\circ}$, with a step of $0.1^{\circ}$ and the registration time of $30 \mathrm{~s}$ per step. Analysis of the WAXS curves and calculation of the degree of crystallinity and dimensions of crystallites was performed using the WAXSFIT computer program [21]. After the background subtraction, the experimental diffraction curves were best fitted by theoretical curves being the sum of functions representing crystalline peaks and an amorphous component. The degree of crystallinity was calculated from the Lorentz corrected curves as the ratio of the integral intensity contained within the crystalline peaks to the total integral intensity scattered by a sample over the whole measurement range. Scherrer's formula was used to calculate the dimensions of crystallites $\left(D_{110}\right)$ and $\left(D_{200}\right)$ perpendicular to the lattice planes (110) and (200), respectively.

Scanning electron microscope (SEM) experiment of the polyethylene samples was carried out on a Hitachi model TM 3000. The samples were fixed on an aluminium sample stub and coated with gold by conventional sputtering techniques. The employed accelerating voltage was $5-15 \mathrm{kV}$ for SEM.

Measurements of positron lifetime spectra were performed using a convectional fast-fast coincidence spectrometer with a time resolution $\sim 270$ ps FWHM (Full Width at Half 
Maximum). This system consists of two scintillation detectors with $\mathrm{BaF}_{2}$ crystals as scintillators. Detectors record the photons emitted from the positron source, i.e. ${ }^{22} \mathrm{Na}$ isotope $0.9 \mathrm{MBq}$ activity enveloped in the Kapton foil ( $\sim \mu \mathrm{m}$ thick), and two identical PE samples, which surround the positron source. Deconvolution of the obtained positron lifetime spectra of the PE samples was performed on four components $\left(\tau_{1}-\right.$ $\left.\tau_{4}\right)$. The PE samples were in form of the thin plates of $1.5 \mathrm{~mm}$ thickness, which were obtained by pressing the powder of polyethylene at $170{ }^{\circ} \mathrm{C}(5 \mathrm{~min}$. at $20 \mathrm{MPa})$, and then, cooled to room temperature.

Ionic liquid synthesis

Synthesis and characteristic $N$ - $n$-alkylpyridinium chloroaluminate ionic liquids were presented in reference [22].

\section{Ethylene polymerization}

All steps were carried out in oxygen-free conditions using an inert nitrogen atmosphere. The ionic liquid $\left(5 \mathrm{~cm}^{3}\right)$ phase was mixed with the alkylaluminium compound and stirred overnight. To investigate the influence of the activator/catalyst molar ratio on the performance of the polymerization reaction, the amount of the alkylaluminium compound $\left(\mathrm{AlEtCl}_{2}\right.$ or $\left.\mathrm{AlEt}_{2} \mathrm{Cl}\right)$ was changed gradually $\left(2.0-6.0 \cdot 10^{-3} \mathrm{~mol}\right.$ of $\left.\mathrm{Al}\right)$ while the amount of the $\mathrm{Cp}_{2} \mathrm{TiCl}_{2}$ catalyst $\left(3.0 \cdot 10^{-5} \mathrm{~mol}\right.$ of Ti) was kept constant. The catalyst was added to the ionic liquid shortly before it was applied to the polymerization reaction. The hexane phase $\left(150 \mathrm{~cm}^{3}\right)$ contained an alkylaluminium compound $\left(2 \cdot 10^{-4} \mathrm{~mol}\right.$ of $\left.\mathrm{Al}\right)$ to act as a scavenger of impurities. The polymerization reaction was conducted in a $500 \mathrm{~cm}^{3}$ glass reactor equipped with a mechanical stirrer and a water jacket to maintain a constant temperature. Hexane and the previously prepared mixture of the ionic liquid/alkylaluminium compound containing $\mathrm{Cp}_{2} \mathrm{TiCl}_{2}$ were added successively into the reactor under a nitrogen atmosphere. The ethylene was bubbled through the ionic liquid phase at a pressure of $5 \mathrm{~atm}$. while the temperature was maintained at $30{ }^{\circ} \mathrm{C}$. The polymerization reaction was terminated by the closure of the ethylene feeding. The hexane phase was decanted. The polyethylene from both phases was filtered off, washed by $5 \% \mathrm{HCl}$ methanolic solution, methanol, and dried at room temperature for $48 \mathrm{~h}$ to constant weight, to obtain a powder, white and off-white from the hexane and ionic liquid phases, respectively.

\section{Catalyst reuse in biphasic system}

The reaction was generally carried out according to the method described for ethylene polymerization. However, after $1 \mathrm{~h}$ of the first cycle, the polymerization was terminated by the closure of the ethylene feeding and the pressure was decreased to the standard conditions. When the ethylene pressure was reduced and stirrer was stopped, separation of the reaction mixture in two phases was observed: the upper phase containing hexane and polyethylene and the bottom ionic liquid phase. In inert nitrogen conditions, free of oxygen and water, the hexane phase containing polyethylene was sucked under reduced pressure (using vacuum pump) by means of a tube, while the ionic liquid phase containing the catalyst was remained in the reactor. The second reaction cycle was performed by introducing a new portion hexane $\left(150 \mathrm{~cm}^{3}\right)$ containing a small amount of the alkylaluminium compound (2.0 . $10^{-4} \mathrm{~mol}$ of Al), which act as a scavenger of impurities. The same procedure was repeated in the third cycle. Each cycle of the polymerization reaction was carried out in the same conditions (temperature: $30^{\circ} \mathrm{C}$, pressure of ethylene: $5 \mathrm{~atm}$., time reaction: $1 \mathrm{~h})$.

\section{Results and discussion}

\section{Ethylene polymerization}

The ethylene polymerization was performed in the biphasic system, in which one phase (bottom) constituted the $N-n$ alkylpyridinium chloroaluminate ionic liquids $\left[\mathrm{C}_{n}\right.$ py] $\left[\mathrm{AlCl}_{4}\right]$, where the $n$-alkyl chain was $n$-butyl, $n$-hexyl, or $n$-octyl. The $\left[\mathrm{C}_{n}\right.$-py] $\left[\mathrm{AlCl}_{4}\right]$ ionic liquids were used as a medium of the $\mathrm{Cp}_{2} \mathrm{TiCl}_{2}$ titanocene catalyst. The polymerization conditions including the $\mathrm{AlEtCl}_{2}$ or $\mathrm{AlEt}_{2} \mathrm{Cl}$ activators were maintained as for the imidazolium ionic liquids [5]. The second (upper) phase was hexane, in which the produced polyethylene was gathered. The catalyst is not present in the hexane phase, but it is maintained in the ionic liquid phase during the polymerization reaction.

Table 1 presents the performance of the biphasic ethylene polymerization using the studied ionic liquids. Generally, the $\mathrm{AlEtCl}{ }_{2}$ activator is better for the titanocene catalyst as compared to $\mathrm{AlEt}_{2} \mathrm{Cl}$. The PE yield depends on the molar ratio activator/catalyst, regardless of the alkyl chain at the pyridinium cation and the kind of the activator. The PE yield increases with the increase of the molar ratio activator/catalyst, but only to an optimal value. This is connected with proper acidity of the ionic liquid phase, necessary for activity of the metallocene catalyst $[6,23]$.

The advantageous feature of the studied $N-n$ alkylpyridinium ionic liquids is the high transfer rate of the $\mathrm{PE}$ product into the hexane phase at lower values of the activator/catalyst molar ratio $(\mathrm{Al} / \mathrm{Ti}=67,100$ and 133$)$. For the $\left[\mathrm{C}_{4}\right.$-py] $\left[\mathrm{AlCl}_{4}\right]$ ionic liquid the highest polymerization activity $(201.6 \mathrm{kgPE} / \mathrm{molTi})$ was obtained at the $\mathrm{Al} / \mathrm{Ti}$ molar ratio 100. For $\left[\mathrm{C}_{6}\right.$-py] $\left[\mathrm{AlCl}_{4}\right]$ and $\left[\mathrm{C}_{8}\right.$-py] $\left[\mathrm{AlCl}_{4}\right]$ the highest 
Table 1 Influence of the polymerization conditions on the activity of the $\mathrm{Cp}_{2} \mathrm{TiCl}_{2}$ catalyst activated by $\mathrm{AlEtCl}_{2}$ or $\mathrm{AlEt}_{2} \mathrm{Cl}$ in biphasic ionic liquid/hexane polymerization of ethylene

\begin{tabular}{lllll}
\hline Item Activator & $\begin{array}{l}\text { Al/Ti molar } \\
\text { ratio }\end{array}$ & Activity (kgPE/molTi) & \\
\cline { 3 - 5 } & & $\begin{array}{l}\text { Ionic liquid } \\
\text { phase }\end{array}$ & $\begin{array}{l}\text { Hexane } \\
\text { phase }\end{array}$ & Tota \\
& & &
\end{tabular}

\section{$\left[\mathrm{C}_{4}\right.$-py $]\left[\mathrm{AlCl}_{4}\right]$}

$1 \quad \mathrm{AlEtCl}_{2}$

$2^{\mathrm{a}}$

$3^{\mathrm{b}}$

$4^{\mathrm{c}}$

5

$6^{\mathrm{d}}$

$7^{\mathrm{a}}$

8

$9^{\mathrm{a}}$

10

11

Catalyst reuse

121 st ste

13 2st step

14 3st step

$15 \quad \mathrm{AlEt}_{2} \mathrm{Cl}$

67

$16^{\mathrm{a}}$

17

18

$19^{\mathrm{a}}$

20

21

$\left[\mathrm{C}_{6}\right.$-py $]\left[\mathrm{AlCl}_{4}\right]$

$22 \quad \mathrm{AlEtCl}_{2}$

$23^{\mathrm{a}}$

$24 \quad 100$

$25 \quad 133$

$26^{\mathrm{a}} \quad 133$

$27 \quad 167$

$28 \quad 200$

$29 \quad \mathrm{AlEt}_{2} \mathrm{Cl} \quad 67$

$30^{\mathrm{a}} \quad 67$

$31 \quad 100$

$32 \quad 133$

$33^{\mathrm{a}} \quad 133$

$34 \quad 167$

$35 \quad 200$

$\left[\mathrm{C}_{8}\right.$-py $]\left[\mathrm{AlCl}_{4}\right]$

$\begin{array}{lrr}36 & \mathrm{AlEtCl}_{2} & 67 \\ 37^{\mathrm{a}} & 67 \\ 38 & & 100 \\ 39 & & 133 \\ 40^{\mathrm{a}} & & 133 \\ 41 & & 167\end{array}$

187.3

158.0

$131.9 \quad 485.4$

$48.0 \quad 50.3$

$51.9 \quad 58.0$

$34.9 \quad 50.3$

$68.3 \quad 76.8$

$80.6 \quad 92.0$

$59.0 \quad 65.0$

$44.9 \quad 51.8$

$48.0 \quad 50.3$

$91.0 \quad 98.0$

$93.6 \quad 107.9$

$161.5 \quad 192.8$

$267.1 \quad 279.0$

$107.0 \quad 149.7$

$106.7 \quad 152.0$

$16.8 \quad 19.5$

$36.2 \quad 41.0$

$31.5 \quad 40.0$

$65.5 \quad 73.8$

$54.2 \quad 65.6$

$28.3 \quad 39.4$

$27.3 \quad 30.6$

$84.0 \quad 91.0$

$69.8 \quad 74.2$

$132.7 \quad 143.4$

$242.3 \quad 255.2$

$133.7 \quad 158.0$
Table 1 (continued)

\begin{tabular}{|c|c|c|c|c|c|}
\hline \multirow[t]{2}{*}{ Item } & \multirow[t]{2}{*}{ Activator } & \multirow{2}{*}{$\begin{array}{l}\mathrm{Al} / \mathrm{Ti} \text { molar } \\
\text { ratio }\end{array}$} & \multicolumn{3}{|c|}{ Activity (kgPE/molTi) } \\
\hline & & & $\begin{array}{l}\text { Ionic liquid } \\
\text { phase }\end{array}$ & $\begin{array}{l}\text { Hexane } \\
\text { phase }\end{array}$ & Total \\
\hline 42 & & 200 & 111.7 & 27.3 & 139.0 \\
\hline 43 & $\mathrm{AlEt}_{2} \mathrm{Cl}$ & 67 & 3.7 & 27.3 & 31.0 \\
\hline $44^{\mathrm{a}}$ & & 67 & 3.7 & 87.3 & 91.0 \\
\hline 45 & & 100 & 10.3 & 31.9 & 42.2 \\
\hline 46 & & 133 & 9.3 & 43.3 & 52.6 \\
\hline $47^{\mathrm{a}}$ & & 133 & 9.5 & 100.5 & 110.0 \\
\hline 48 & & 167 & 11.3 & 67.0 & 78.3 \\
\hline 49 & & 200 & 10.3 & 50.7 & 61.0 \\
\hline
\end{tabular}

Polymerization conditions: $5 \mathrm{~cm}^{3}$ of ionic liquid, $150 \mathrm{~cm}^{3}$ of hexane, 3.0 $\cdot 10^{-5} \mathrm{~mol}$ of catalyst, $5 \mathrm{~atm}$ of ethylene, $30{ }^{\circ} \mathrm{C}, 60 \mathrm{~min}$

a $120 \mathrm{~min}$

b $30 \mathrm{~min}$

c $45 \mathrm{~min}$

d $90 \mathrm{~min}$

$22.3 \quad 26.5$ activities (192.8 and $158.0 \mathrm{kgPE} / \mathrm{molTi})$ were obtained at $\mathrm{Al} /$ $\mathrm{Ti}=133$ and 167, respectively. Further increase of the $\mathrm{Al} / \mathrm{Ti}$ molar ratio results in decrease of the product yield as well as in an undesirable increase of the PE remaining in the ionic liquid phase. This shows that the lengthening of the alkyl substituent at the ionic liquids cation decreases the amount of the polymer obtained. It can be clearly seen at lower $\mathrm{Al} / \mathrm{Ti}$ molar ratio (67 and 100). The highest yield is obtained using the $\left[\mathrm{C}_{4}-\right.$ py] $\left[\mathrm{AlCl}_{4}\right]$ ionic liquid, regardless of the kind of the activator.

Further improvement of the polymerization performance can be obtained by prolongation of the polymerization time. This not only increases the total amount of the obtained polymer, but also improves the mass transfer of the polymer product to the hexane phase (Table 1). The most effective system containing $\left[\mathrm{C}_{4}\right.$-py] $\left[\mathrm{AlCl}_{4}\right]$ and $\mathrm{AlEtCl}_{2}$ was used to investigate the influence of the gradual prolongation of the polymerization time on the PE yield (Table 1, items 3-7). Increase of the polymerization time from 30 to $120 \mathrm{~min}$. results in increase of the amount of the PE product. Such behavior is typical for very stable supported organometallic catalytic systems [24-26] and proves that the $\mathrm{Cp}_{2} \mathrm{TiCl}_{2}$ catalyst is firmly immobilized in the pyridinium chloroaluminate phase.

Another way to increase the catalyst performance in biphasic polymerization is the reuse of the ionic liquid phase containing the catalyst system. The reuse of the ionic liquid phase was tested on the 3-cycle ethylene polymerization using reaction parameters $(\mathrm{Al} / \mathrm{Ti}=100 \mathrm{~mol} / \mathrm{mol})$ that are optimal for system with $\left[\mathrm{C}_{4}\right.$-py $]\left[\mathrm{AlCl}_{4}\right]$ and $\mathrm{AlEtCl}{ }_{2}$ (Table 1, items 12 14). The amount of the polyethylene obtained from the hexane 
phase decrease from step to step, which seems to be connected with some difficulties at the laboratory scale. However, the total activity in all cycles reaches about a half tone of polyethylene per mole of the catalyst. It is the highest amount of the polymer product obtained in the studied biphasic processes. Moreover, the possibility to apply the ionic liquid phase in the multiple polymerization cycles also indicates a considerable stability of the titanocene catalyst immobilized in the ionic liquid phase.

The activities obtained using the pyridinium chloroaluminate ionic liquids are greater than those obtained using the imidazolium analogues, when the same activator and catalyst were applied [5]. Moreover, the phase separation is much easier and the transfer rate of the PE product from the ionic liquid phase to hexane is greater when the studied pyridinium ionic liquids are used. These are important aspects of the biphasic process.

This effect can be explained by the physical properties of the studied ionic liquids, especially by their viscosity and density [22], that have an effect on the performance of the biphasic systems [5, 6, 27].

Densities of the studied $\left[\mathrm{C}_{\mathrm{n}}\right.$-py] $\left[\mathrm{AlCl}_{4}\right]$ ionic liquids $\left(1.2763,1.2128,1.1915 \mathrm{~g} / \mathrm{cm}^{3}\right.$, respectively for $n=4,6$, and 8 ) are considerably higher at the reaction temperature $\left(30^{\circ} \mathrm{C}\right)$ than those for 1-n-alkyl-4-methylpyridinium $\left[\mathrm{C}_{\mathrm{n}}-4\right.$ mpy][$\left[\mathrm{AlCl}_{4}\right]\left(1.2021,1.1430,1.1200 \mathrm{~g} / \mathrm{cm}^{3}\right.$ for $n=4,6$, and 8) as well as 1-n-alkyl-3-methylimidazolium $\left[\mathrm{C}_{\mathrm{n}}\right.$ $\operatorname{mim}]\left[\mathrm{AlCl}_{4}\right]\left(1.2416,1.1806,1.1192 \mathrm{~g} / \mathrm{cm}^{3}\right.$ for $n=4,6$, and 8 ) analogues [22]. It results from the lack of additional methyl substituent at the aromatic cation, which allows to pack more tightly the ionic liquid molecules. There is also considerable difference in density of the ionic liquid with $n$-butyl $\left(\mathrm{C}_{4}\right)$ substituent than $n$-hexyl $\left(\mathrm{C}_{6}\right)$ or $n$-octyl $\left(\mathrm{C}_{8}\right)$, which can be explained by more tight aggregation of the shorter alkyl chains [28]. The considerable high density of the $\left[\mathrm{C}_{4}\right.$-py] $\left[\mathrm{AlCl}_{4}\right]$ ionic liquid results in greater differences between the ionic liquid and hexane phases, and in consequence, their separation is more easy.

On the other hand, viscosities of the studied $\left[\mathrm{C}_{\mathrm{n}^{-}}\right.$ py] $\left[\mathrm{AlCl}_{4}\right]$ ionic liquids $(34.5,49.4,56.2 \mathrm{mPa} \cdot \mathrm{s}$, respectively for $n=4,6$, and 8 ) are comparable to $\left[\mathrm{C}_{\mathrm{n}}-4\right.$ mpy][$\left[\mathrm{AlCl}_{4}\right](34.8,48.9,84.0 \mathrm{mPa} \cdot \mathrm{s}$, respectively for $n=4,6$, and 8) and somehow higher than $\left[\mathrm{C}_{\mathrm{n}}-\mathrm{mim}\right]\left[\mathrm{AlCl}_{4}\right]$ (25.0, 47.3, $64.7 \mathrm{mPa} \cdot \mathrm{s}$, respectively for $n=4,6$, and 8) analogues [22]. Obviously, the viscosity increases with the length of the alkyl substituent because higher energy barrier must be overcome by molecules in order to move past each other. It is very important for the biphasic polymerization because the produced PE should be easily transferred to the hexane phase. The relative high density and low viscosity of the studied $\left[\mathrm{C}_{4}\right.$-py] $\left[\mathrm{AlCl}_{4}\right]$ ionic liquid enable easy separation of the ionic liquid phase and at the same time, easy transfer of the produced PE.
Polyethylene properties

At the beginning of the polymerization reaction whitening and swelling of the ionic liquid phase is observed whereas the hexane phase remains colorless and transparent. After 5 to $10 \mathrm{~min}$ of the reaction, the produced polyethylene was transferred from the ionic liquid phase into the hexane phase, which enables to separate the product easily by means of simple decantation. This determines the high purity of the polyethylene produced.

Polyethylene, which was gathered from the hexane phase, has the form of pure white powder and was analyzed without any further purification. The results of analyses are presented in Table 2.

The produced polyethylene is a linear polymer, regardless of the alkyl chain at the pyridinium cation. This indicates the singlet of methylene groups at $\delta=29.9 \mathrm{ppm}\left({ }^{13} \mathrm{C} \mathrm{NMR}\right)$. The number of branches (from 6.8 to 9.7 of the methyl groups per 1000 methylene groups) is comparable for all the samples analyzed, as determined by ${ }^{1} \mathrm{H}$ NMR and FTIR analyses. The number of branches increases with increase of the activator concentration, regardless of the ionic liquid used.

Melting temperature of the polyethylene samples varies in the range of $124-138^{\circ} \mathrm{C}$.

Molecular weight $\left(\mathrm{M}_{\mathrm{w}}\right)$ of the PE produced varies from 22600 to $121200 \mathrm{~g} / \mathrm{mol}$. It depends on the polymerization time, kind of the ionic liquid, kind of the activator, and activator/catalyst molar ratio. The molecular weight increases with polymerization time. This is common for polymer products obtained using organometallic catalysts [25]. Polyethylene obtained in $\left[\mathrm{C}_{4}-\mathrm{py}\right]\left[\mathrm{AlCl}_{4}\right]$ is characterized by higher molecular weight than that obtained using $\left[\mathrm{C}_{6}\right.$-py $]\left[\mathrm{AlCl}_{4}\right]$ and $\left[\mathrm{C}_{8}\right.$-py] $\left[\mathrm{AlCl}_{4}\right]$. Thus, longer alkyl substituents at the pyridinium cation decrease this parameter. Lower $\mathrm{M}_{\mathrm{w}}$ values are obtained using the $\mathrm{AlEt}_{2} \mathrm{Cl}$ activator instead of $\mathrm{AlEtCl}_{2}$.

The molecular weight also decreases with increase of the activator/catalyst molar ratio. This indicates that the alkylaluminium compound participates, most probably, in the chain termination reaction. To confirm this effect, the kind of the terminal groups in the polymer chain was determined using ${ }^{1} \mathrm{H}$ NMR method. Figure 1 presents ${ }^{1} \mathrm{H}$ NMR spectra of the PE samples obtained in the biphasic process. Apart of the strong signal about $1.30 \mathrm{ppm}$ ascribed to methylene groups ($\mathrm{CH}_{2}-$ ), the much weaker signals are seen, resulting from the presence of vinyl groups (4.87-4.97 ppm), allylic methylene groups (2.01-2.06 ppm), and methyl groups ( $0.85 \mathrm{ppm})$. The signal at $3.53 \mathrm{ppm}$ indicates the presence of hydroxyl groups $(-\mathrm{OH})$ in the polymer chain $[6,29,30]$.

The molecular weight distributions $\left(\mathrm{M}_{\mathrm{w}} / \mathrm{M}_{\mathrm{n}}\right)$ of the studied samples are monomodal but relatively broad, from 3.6 to 7.9. This is characteristic for the polymer obtained using supported metallocene catalysts $[25,31,32]$. 
Table 2 Selected properties of the PE obtained from the hexane phase using the $\mathrm{Cp}_{2} \mathrm{TiCl}_{2}$ catalyst in the biphasic ionic liquid/hexane polymerization

\begin{tabular}{|c|c|c|c|c|c|c|c|}
\hline Item $^{\mathrm{e}}$ & $\mathrm{Al} / \mathrm{Ti}$ molar ratio & $\mathrm{T}_{\mathrm{m}}\left({ }^{\circ} \mathrm{C}\right)$ & Crystallinity (DSC) (\%) & $\mathrm{M}_{\mathrm{w}} \cdot 10^{-3}(\mathrm{~g} / \mathrm{mol})$ & $\mathrm{M}_{\mathrm{w}} / \mathrm{M}_{\mathrm{n}}$ & Bulk density $\left(\mathrm{g} / \mathrm{dm}^{3}\right)$ & $\mathrm{CH}_{3} / 1000 \mathrm{CH}_{2}$ \\
\hline \multicolumn{8}{|c|}{$\left[\mathrm{C}_{4}\right.$-py $]\left[\mathrm{AlCl}_{4}\right]$} \\
\hline 1 & 67 & 134 & 92.2 & 121.2 & 5.3 & 397 & 7.7 \\
\hline 5 & 100 & 134 & 91.4 & 105.1 & 5.6 & 454 & 9.7 \\
\hline 8 & 133 & 133 & 90.5 & 72.6 & 5.7 & 479 & 8.7 \\
\hline 9 & 133 & 134 & 88.6 & 116.7 & 6.1 & 665 & 8.7 \\
\hline 10 & 167 & 133 & 86.3 & 72.5 & 6.6 & 527 & 8.7 \\
\hline 11 & 200 & 134 & 80.2 & 55.4 & 7.9 & 617 & 8.7 \\
\hline 15 & 67 & 133 & 83.0 & 91.7 & 5.6 & 182 & 7.7 \\
\hline 16 & 67 & 132 & 88.6 & 104.0 & 4.6 & 295 & 7.7 \\
\hline 17 & 100 & 132 & 85.1 & 72.0 & 4.9 & 222 & 7.7 \\
\hline 18 & 133 & 132 & 82.9 & 111.8 & 4.6 & 190 & 7.7 \\
\hline 19 & 133 & 134 & 80.6 & 119.8 & 4.0 & 268 & 7.7 \\
\hline 20 & 167 & 131 & 89.1 & 66.6 & 3.6 & 172 & 7.7 \\
\hline 21 & 200 & 132 & 90.6 & 69.6 & 3.6 & 139 & 7.7 \\
\hline \multicolumn{8}{|c|}{$\left[\mathrm{C}_{6}-\mathrm{py}\right]\left[\mathrm{AlCl}_{4}\right]$} \\
\hline 24 & 100 & 125 & 90.4 & nd & nd & 127 & 6.8 \\
\hline 25 & 133 & 130 & 84.9 & 51.7 & 6.8 & 208 & 8.7 \\
\hline 26 & 133 & 131 & 82.0 & 58.8 & 5.5 & 514 & 8.7 \\
\hline 27 & 167 & 131 & 83.0 & nd & nd & 254 & 8.7 \\
\hline 28 & 200 & 131 & 92.4 & 40.6 & 6.9 & 491 & 8.7 \\
\hline 32 & 133 & 127 & 74.3 & 34.5 & 6.6 & 140 & nd \\
\hline 33 & 133 & 124 & 81.4 & nd & nd & 174 & 6.8 \\
\hline 34 & 167 & 127 & 85.0 & 22.6 & 6.6 & 174 & 7.7 \\
\hline 35 & 200 & 128 & 90.7 & 24.6 & 6.6 & 170 & 8.7 \\
\hline \multicolumn{8}{|c|}{$\left[\mathrm{C}_{8}-\mathrm{py}\right]\left[\mathrm{AlCl}_{4}\right]$} \\
\hline 38 & 100 & 138 & 74.6 & 100.6 & 4.4 & 441 & 7.7 \\
\hline 39 & 133 & 134 & 71.1 & 77.5 & 4.4 & 463 & 7.7 \\
\hline 42 & 200 & 133 & 78.3 & 45.6 & 7.5 & 531 & 8.7 \\
\hline 45 & 100 & 130 & 66.3 & 34.2 & 7.0 & 150 & 8.7 \\
\hline 46 & 133 & 131 & 66.4 & 39.4 & 6.4 & 171 & nd \\
\hline 48 & 167 & 132 & 66.9 & 36.1 & 6.4 & 229 & 8.7 \\
\hline 49 & 200 & 132 & 66.5 & 37.7 & 6.2 & 295 & 8.7 \\
\hline
\end{tabular}

e numeration according Table 1

$n d$ not determined

A distinguishing feature of the PE produced is the high bulk density, which reaches a value up to $665 \mathrm{~g} / \mathrm{dm}^{3}$. The bulk density of the polymer depends on length of the alkyl substituent at the pyridinium cation as well as kind and concentration of the activator. The highest values of the bulk density are obtained using $\left[\mathrm{C}_{4}\right.$-py] $\left[\mathrm{AlCl}_{4}\right]$ ionic liquids and $\mathrm{AlEtCl}_{2}$. The bulk density increases with an increase of the reaction time, but decreases with an increase of the activator/catalyst molar ratio. It should be noticed, however, that such high values of the PE bulk density can be obtained only for the heterogeneous metallocene catalyst $[25,31,32]$. In the case of the homogeneous systems, the bulk density usually does not exceed $100 \mathrm{~g} / \mathrm{dm}^{3}[33,34]$.
Figure 2 presents the SEM photo of the polyethylene samples. As can be seen, the polyethylene produced in the biphasic mode using chloroaluminate pyridinium ionic liquids has the shape of regular granules, similar to those obtained using organometallic catalysts anchored on a solid carrier [32, 35].

The high crystallinity, determined by the DCS and WAXS methods, is characteristic feature of the PE produced in the ionic liquid phase. In DSC measurements, first heatingcooling-second heating runs are made. The first heating scan cycle was done in order to eliminate thermal history of the sample, that applied the polymer synthesis and processing, and also to eliminate moisture content. So, the second heating 


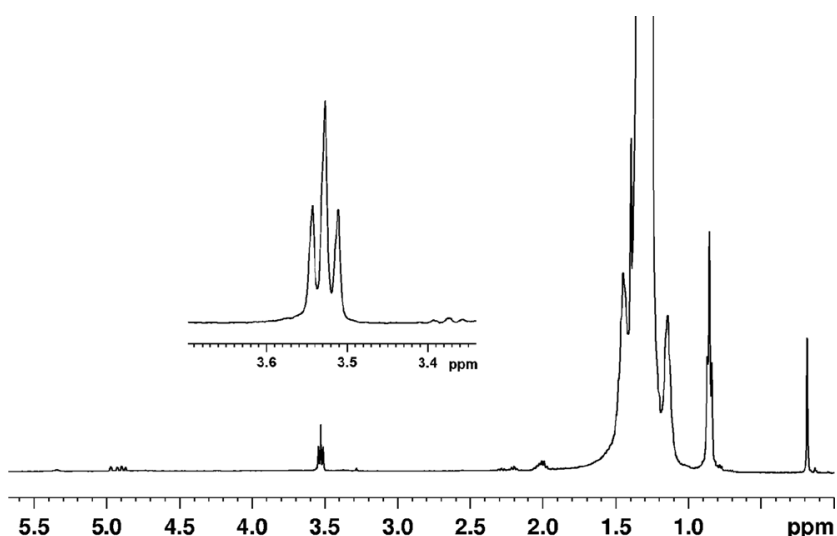

Fig. $1{ }^{1} \mathrm{H}$ NMR spectra of the polyethylene obtained in the biphasic polymerization using the $\mathrm{Cp}_{2} \mathrm{TiCl}_{2}$ catalyst, $\left[\mathrm{C}_{4}\right.$-py] $\left[\mathrm{AlCl}_{4}\right]$ ionic liquid, and $\mathrm{AlEtCl}_{2}$ activator $(\mathrm{Al} / \mathrm{Ti}=133 \mathrm{~mol} / \mathrm{mol})$ (item 8 according to Table 1$)$

was used in this DSC analysis [36-38]. Nevertheless, the differences between the measurements after first and second runs for the studied PE samples are relatively small. After
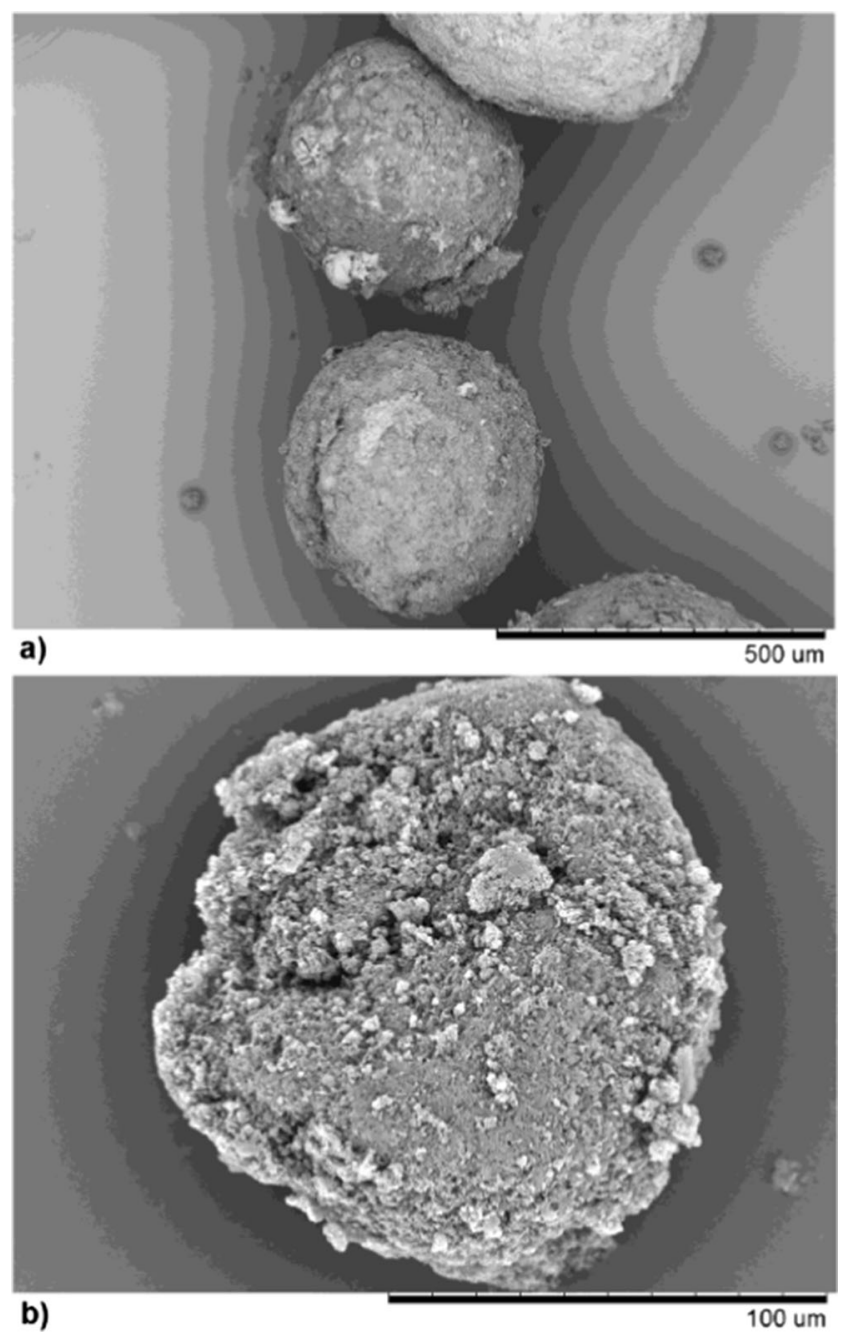

Fig. 2 SEM images of the PE sample (item 8 according to Table 1) eliminating thermal history, the melting temperatures and crystallinity degree of the PE samples are little higher, up to 2 and $10 \%$, respectively. Therefore, differences in the melting temperature and crystallinity degree of the obtained polyethylene depend on the polymerization conditions (type of the ionic liquid, the activator/catalyst molar ratio) than on the procedure of the DSC measurement. According to the DCS method the crystallinity degree is in the range from 66.3 to $92.4 \%$ (Table 2), and the PE samples from the hexane phase reveal high purity as shown by an example from the DSC thermograms (Fig. 3).

Diffractograms WAXS depict the distribution of the diffracted X-ray intensity on the test polymer as a function of diffraction angle $2 \theta$. Crystallinity degree of the PE samples was determined by distribution of the diffractograms on the reflections coming from the crystallites and the broad peaks originating from the amorphous phase. The diffractogams were analyzed using WAXFIT computer program. In the procedure of deconvolution of diffraction curves, the experimental curve is approximated by a theoretical function consisted of component functions. Each of the component function represent the individual element of the diffractogram. Both peaks from crystal phase and maxima from amorphous phase are describes by the function, which is a combination of Gauss and Lorentz functions:

$$
\begin{aligned}
F_{i}(x)= & f_{i} H_{i} \exp \left\{-\ln 2\left[\frac{2\left(x-x_{o i}\right)}{w_{i}}\right]^{2}\right\} \\
& +\frac{\left(1-f_{i}\right) H_{i}}{1+\left[2\left(x-x_{o i}\right) / w_{i}\right]^{2}}
\end{aligned}
$$

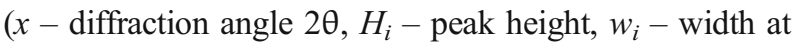
half maximum, $x_{o i}$ - peak position, $f_{i}$ - shape factor equal 1 for Gaussian curve and 0 for Lorentz curve)

The crystallinity degree was calculated as the ratio of the area under the crystalline peaks to the total area under

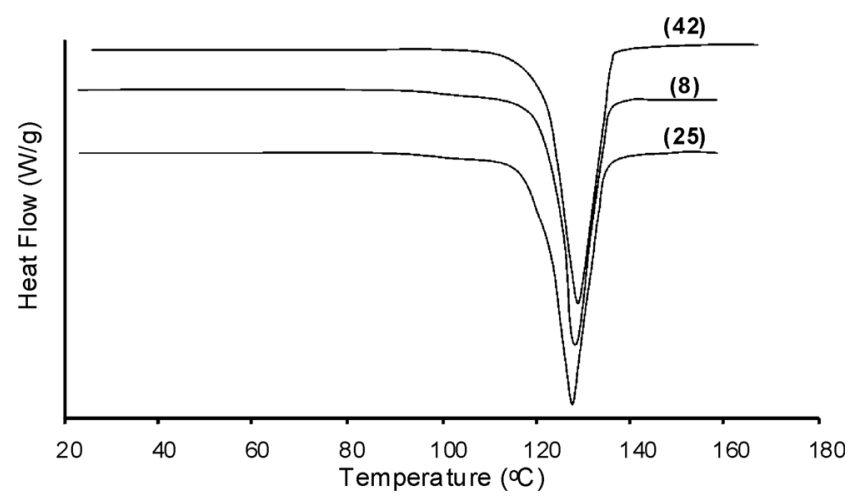

Fig. 3 DSC of the PE samples (item 8, 25, and 42 according to Table 1) 
diffractograms (after background subtraction and Lorentz correction). Using Scherrer equation:

$D_{h k l}=\frac{\lambda}{w \cdot \cos \theta}$

( $\lambda$ - wavelength, $w$ - width at half maximum of the peak for the lattice planes). Dimension of crystallites were calculated in a direction perpendicular to the lattice planes (110) and (200).

The WAXS measurement estimates the value to be about $80 \%$ (Table 3, Figs. 4 and 5). The diffractograms of the studied PE samples are very similar indicating very small differences in their crystallinity degree. The results of the analysis of the selected sample (item 5) are depicted in Fig. 5. It shows the maximum of amorphous phase (A) and two highest crystal peaks. The calculated crystallinity degree equal $80 \%$. Such a high crystallinity is atypical for the PE obtained using metallocene catalysts [39] and it corresponds to that of the commercial HDPE (crystallinity = 70-90\%) obtained using Ziegler-Natta catalysts [14, 15]. However, the sizes of the crystallites are quite small. They were estimated to vary from 165 to $178 \mathrm{~nm}$ in the direction perpendicular to the (200) lattice planes and from 188 to $206 \mathrm{~nm}$ in the direction perpendicular to the (110) planes (Table 3, Figs. 4 and 5). It seems that they do not depend on the studied ionic liquid.

The differences in the crystallinity degree values obtained from the DSC and WAXS methods results primarily from their specificity. In DSC analysis, the crystallinity degree is obtained by measurement of absorbed heat of fusion of the crystal phase, which is described by the peak area. All crystallites, even the smallest, have their contribution in the measured heat of fusion. Therefore, the value of the crystallinity degree determined by DSC method is relatively high. In WAXS method, reflections from very small crystallites are broadly distributed in diffractograms so that they overlap with components from the amorphous phase. Therefore, the value of the crystallinity degree determined by the WAXS method is lower in comparison to the DSC method.

Table 3 Crystallity degree and crystallite size of PE determined by WAXS method

\begin{tabular}{lccccc}
\hline Parameters & \multicolumn{5}{l}{ Polyethylene samples } \\
\cline { 2 - 6 } & Item 5 & Item 8 & Item 11 & Item 24 & Item 42 \\
\hline Crystallity degree, (\%) & 80 & 80 & 77 & 80 & 79 \\
Crystallite size, & & & & & \\
$D_{100}(\mathrm{~nm})$ & 206 & 197 & 190 & 190 & 188 \\
$\mathrm{D}_{200}(\mathrm{~nm})$ & 178 & 168 & 165 & 165 & 166 \\
\hline
\end{tabular}

e numeration according Table 1

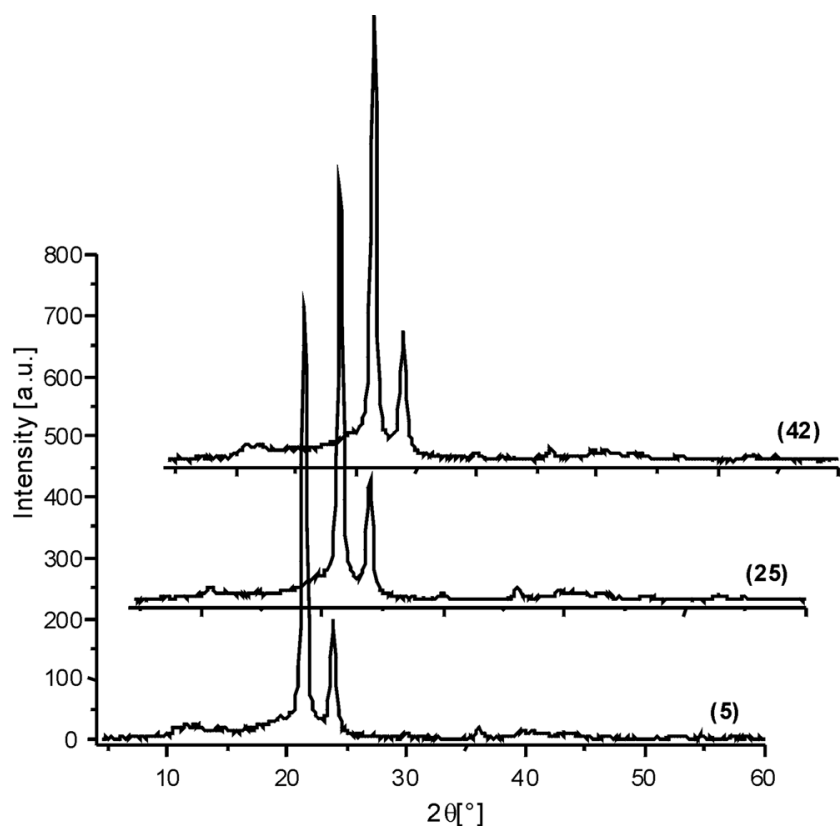

Fig. 4 X-ray diffraction patterns of the PE samples (item 5, 25, and 42 according to Table 1)

In the present study we have also analyzed subnanometersized local free volume holes in polymer materials by positron annihilation lifetime spectroscopy (PALS). Polymers contain local free volumes as cavities or holes of atomic and molecular dimensions, which appear because of the structural disorder in the amorphous polymer structure [16]. The positronium atom (Ps), that is an electron-positron bound state, is formed and annihilates preferentially in the local free-volume region between molecules. The values of the components of annihilation spectra, i.e. lifetime positronium $\tau_{i}$ and intensity of those components $I_{i}$ (where $i$ - number of components) are associated with certain properties of the open volume defects, in

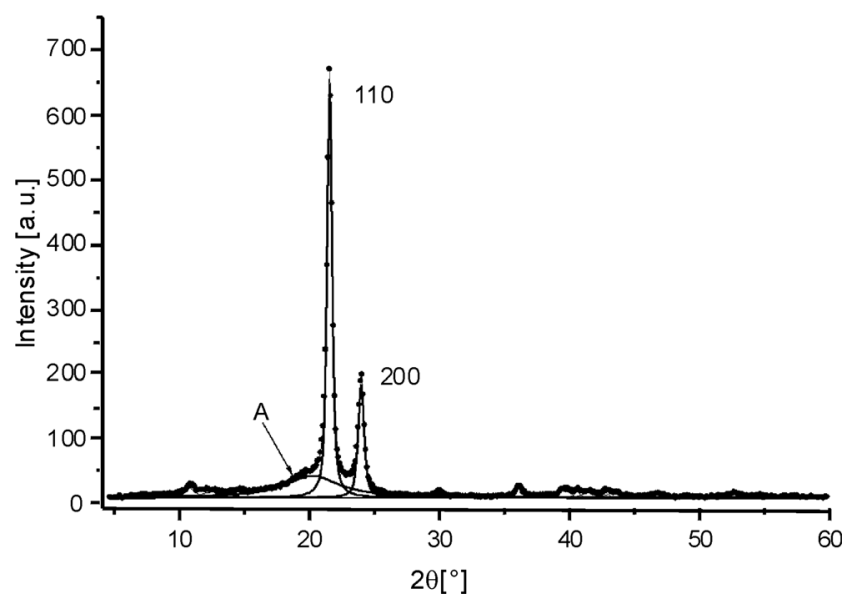

Fig. 5 X-ray diffraction of the PE sample (item 5 according to Table 1) resolved into crystalline peaks and amorphous component; points - experimental curve, solid line - theoretical best fitted curve. Two strongest peaks: 110 and 200, as well as the amorphous component (A) are indicated 
which the positron annihilates. The positrons lifetime depends on the size of the open volume defects, whereas the intensity of the component of positrons lifetimes spectra, responsible for annihilation in the defects, depends on their concentration [40]. In this work the deconvolution of spectrum of lifetime positronium was performed on four components $\left(\tau_{1}-\tau_{4}\right)$ [14, 41]. It is assumed that the shortest lifetime $\tau_{1}$ is attributed to the para-positronium ( $p$-Ps), the second lifetime component $\tau_{2}$ is supposed to be due to free positron annihilation, and two longest-lived components $\tau_{3}$ and $\tau_{4}$ are considered to originate from ortho-positronium (o-Ps) annihilation in crystalline and amorphous regions of the polymer, respectively [14, 15, 41].

Table 4 shows the values of components $\tau_{2}, \tau_{3}$ and $\tau_{4}$, intensity of those components $\left(I_{2}, I_{3}\right.$ and $\left.I_{4}\right)$, hole radius $(R)$, volumes for free-volume holes $\left(V_{v}\right)$, and free-volume fractions $\left(f_{v}\right)$ obtained for polyethylene produced using the studied pyridinium ionic liquids. Radius of the holes was calculated from the semi-empirical equation:

$\tau_{4}=0.5\left[1-\frac{R}{R+0.166}+\frac{1}{2 \pi} \sin \left(2 \pi \frac{R}{R+0.166}\right)\right]^{-1}$

The values of $f_{v}$ were calculated using equation:

$f_{v}=a \cdot V_{v} \cdot I_{4}$

where $a=0.0018$ is an empirical parameter, and $V_{v}$ is determined from equation, that based on a crude model of particle in a spherical box:

$V_{v}=4 \cdot \pi \cdot R^{3} / 3$

Table 4 The parameters determined by PALS analysis for PE produced using ionic liquid

e numeration according Table 1

\begin{tabular}{lcc}
\hline Parameters & \multicolumn{2}{l}{ Polyethylene samples ${ }^{\mathrm{e}}$} \\
\cline { 2 - 3 } & Item 5 & Item 11 \\
\hline$\tau_{2}(\mathrm{~ns})$ & 0.359 & 0.311 \\
& $(0.065)$ & $(0.009)$ \\
$I_{2}(\%)$ & 68.3 & 65.0 \\
& $(1.0)$ & $(1.7)$ \\
$\tau_{3}(\mathrm{~ns})$ & 1.26 & 0.781 \\
& $(0.32)$ & $(0.075)$ \\
$I_{3}(\%)$ & 12.36 & 14.1 \\
& $(0.69)$ & $(1.6)$ \\
$\tau_{4}(\mathrm{~ns})$ & 2.73 & 2.20 \\
& $(0.31)$ & $(0.04)$ \\
$I_{4}(\%)$ & 10.1 & 14.0 \\
& $(1.0)$ & $(0.65)$ \\
$R(\mathrm{~nm})$ & 0.344 & 0.302 \\
& $(0.023)$ & $(0.003)$ \\
$\left.V_{\mathrm{v}}(\mathrm{nm})^{3}\right)$ & 0.1705 & 0.1153 \\
$f_{v}(\%)$ & 3.10 & 2.91 \\
\hline
\end{tabular}

The small values of radius of the holes and intensity of the $\tau_{4}$ components are comparable to values for commercial linear polyethylene $\left(\mathrm{M}_{\mathrm{w}}=1 \cdot 10^{5} \mathrm{~g} / \mathrm{mol}, \mathrm{M}_{\mathrm{w}} / \mathrm{M}_{\mathrm{n}}=3\right)$, which was subjected to a specific thermal treatment [14]. Moreover, these values indicate the high crystallinity $(77-80 \%)$ of the PE obtained. However, the sizes of the crystallites determined by WAXS measurement for the analyzed PE samples were two times smaller in comparison to results obtained for commercial polyethylene [14, 15].

The high crystallinity degree of the PE obtained using the ionic liquid was independently confirmed by DCS, WAXS, and PALS methods. The high crystallinity degree of PE seems to be an effect of the ionic liquid environment. The ionic liquids - salts, which low melting temperature is due to the low-symmetry organic cations reducing the lattice energy, exhibit specific nano-structural organization [28, 42-44]. The molecular structure of the ionic liquids lead to formation of nano-scale polar domains created by ionic parts of the ionic liquid molecules, permeated by non-polar regions created by the alkyl side chains at the aromatic rings of the ionic liquid cations. Existence of such inhomogeneity characterized by ionic network and nonpolar regions, allows regarding the ionic liquids as "two-in-one" solvents, with each domain acting as a specific solvent for a given class of solutes: dipolar or associating solutes will interact with the polar network, whereas non-polar molecules will be solvated and tend to dissolve in the non-polar regions [44]. Such feature of the ionic liquids makes possible to apply them as the medium of the catalyst for olefin polymerization. The polar catalyst and activator are dissolved, and efficiently maintained, in the polar high charged regions characterized by ionic interactions. This allows creating cationic species with transition metal, which are able to perform the polymerization reaction. On the other hand, the ethylene monomer is dissolved in the non-polar regions of the alkyl side chains characterized by dispersive forces. The permeation of both polar and non-polar domains allows access of the non-polar monomer to the polar active species. The resulting polyethylene chains constitute nonpolar domains. However, the high-charge ionic network, responsible for the aggregation of the side chains in non-polar domains [43], promotes polyethylene chain packing at the stage of its synthesis. This explains the high crystallinity degree of the produced polyethylene. Furthermore, the nanoscale size of the ionic liquids domains can explain small size of crystallites determined by the WAXS method.

\section{Conclusions}

The $N$ - $n$-alkylpyridinium chloroaluminate ionic liquids $\left[\mathrm{C}_{\mathrm{n}}\right.$ py] $\left[\mathrm{AlCl}_{4}\right]$ (where $n$-alkyl $=n$-butyl, $n$-hexyl, and $n$-octyl) were applied for the first time as the medium of the 
$\mathrm{Cp}_{2} \mathrm{TiCl}_{2}$ catalyst and common alkylaluminium activator $\left(\mathrm{AlEtCl}_{2}, \mathrm{AlEt}_{2} \mathrm{Cl}\right)$ and was found to improve considerably the performance of the biphasic ethylene polymerization, as compared to the previously studied ionic liquids. In particular, the most effective was the system with $\left[\mathrm{C}_{4}\right.$-py] $\left[\mathrm{AlCl}_{4}\right]$ and $\mathrm{AlEtCl}_{2}$. The $N$ - $n$-butylpyridinium chloroaluminate ionic liquid $\left[\mathrm{C}_{4}\right.$-py $]\left[\mathrm{AlCl}_{4}\right]$ is characterized by relatively high density, which enables efficient separation of the phases, and simultaneously relatively low viscosity, which facilitates efficient mass transfer of the polymer product from the ionic liquid phase to hexane. The prolongation of the polymerization time and the possible reuse of the ionic liquid phase lead to further improvement of the polymerization performance and indicate a stability of the titanocene catalyst immobilized in the ionic liquid.

The presented results indicate that the application of the ionic liquid as the medium of the catalyst for ethylene polymerization is the promising way to obtain the polymer product characterized by unique and interesting properties obtained at the stage of its synthesis. Dual, polar/non-polar structural organization of the ionic liquids makes possible to anchor efficiently the catalyst in the ionic liquid medium. The high crystallinity degree and bulk density as well as regular shape of granules of the produced polyethylene results from the packing of the polyethylene chain at the stage of its synthesis.

The studied pyridinium ionic liquids as a medium for metallocene catalyst gives an alternative product to polymer that is usually produced by using heterogeneous catalyst on a solid carrier.

Open Access This article is distributed under the terms of the Creative Commons Attribution License which permits any use, distribution, and reproduction in any medium, provided the original author(s) and the source are credited.

\section{References}

1. Qiao J, Guo M, Wang L, Liu D, Zhang X, Yu L, Song W, Liu Y (2011) Polym Chem 2:1611-1632

2. Nomura K, Liu J, Padmanabhan S, Kitiyanan B (2007) J Mol Catal A 267:1-29

3. Choi Y, Soares JBP (2012) Can J Chem Eng 90:646-671

4. Jiang B, Yang Y, Du L, Wang J, Yang Y, Stapf S (2013) Ind Eng Chem Res 52:2501-2509

5. Ochędzan-Siodłak W, Dziubek K, Siodłak D (2008) Eur Polym J 44: 3608-3614

6. Ochędzan-Siodłak W, Dziubek K, Czaja K (2013) Polym Bull 70:121

7. Crosthwaite JM, Muldoon MJ, Dixon JNK, Anderson JL, Brennecke JF (2005) J Chem Thermodyn 37:559-568

8. Cadena C, Zhao Q, Snurr RQ, Maginn EJ (2006) J Phys Chem B 110: 2821-2832
9. Dong F, Yang LF, Yang JM (2013) Res Chem Intermed 39:25052511

10. Calvara N, Gómez E, Macedo EA, Domínguez Á (2013) Thermochim Acta 565:178-182

11. Bittner B, Wrobel RJ, Milchert E (2012) J Chem Thermodyn 55:159165

12. Barron D, Birkinshaw C (2009) Polym Degrad Stab 94:1621-1631

13. Barron D, Birkinshaw C (2008) Polymer 49:3111-3115

14. Dlubek G, Stejny J, Lüpke T, Bamford D, Petters K, Hubner CH, Alam MA, Hill MJ (2002) J Polym Sci B Polym Phys 40:65-81

15. Dlubek G, Bamford D, Rodrigues-Gonzales A, Bornemann S, Stejny J, Schade B, Alam MA, Alnold J (2002) J Polym Sci B Polym Phys 40:434-453

16. Bamford D, Dlubek G, Lüpke T, Kilburn D, Stejny J, Tammo J, Menke TJ, Alam MA (2006) Macromol Chem Phys 207:492-502

17. Jean YC, van Horn JD, Hung WS, Lee KR (2013) Macromolecules 46:7133-7145

18. Widman G, Riesen R (1987) In: Oehme F (ed) Thermal analysis: terms, methods, applications. Dr Alfred Hüthing, Verlag, p 23

19. Scheirs J (2000) Compositional and failure analysis of polymers: a practical approach. Wiley, Chichester, p 115

20. Blaine RL (2001) In: Riga AT, Judovits L (eds), Materials characterization by dynamic and modulated thermal analytical techniques, ASTM: STP1402, Baltimore, p 125

21. Rabiej S (2005) Eur Polym J 41:393-402

22. Ochędzan-Siodłak W, Dziubek K, Siodłak D (2013) J Mol Liq 177: 85-93

23. Carlin RT, Wilkes JS (1990) J Mol Catal 63:125-129

24. Kaminsky W, Winkelbach H (1999) Top Catal 7:61-67

25. Ochędzan-Siodłak W, Nowakowska M (2005) Eur Polym J 41:941947

26. De Freitas JD, dos Santos JHZ, Meneghetti SMP, Meneghetti MR (2011) J Appl Polym Sci 119:3051-3057

27. Wasserscheid P (2007) J Ind Eng Chem 13:325-338

28. Triolo A, Russina O, Bleif HJ, Di Cola E (2007) J Phys Chem B 111: 4641-4644

29. Liu J, Stovneng JA, Rytter E (2011) J Polym Sci A Polym Chem 39: 3566-3577

30. Babu GN, Newmark RA, Chien JCW (1994) Macromolecules 27: 3383-3388

31. Kang KK, Oh JK, Jeong YT, Shiono T, Ikeda T (1999) Macromol Rapid Commun 20:308-311

32. Hammawa H, Wanke SE (2006) Polym Int 55:426-434

33. Soares JBP, Kim JDJ (2000) J Polym Sci Chem 38:1408-1416

34. Lee BY, Oh JS (2000) Macromolecules 33:3194-3195

35. Huang R, Duchateau R, Koning CE, Chadwick JC (2008) Macromolecules 41:579-590

36. Qi M, Yao F, Zheng J, Qian R (1993) J Therm Anal 40:783-789

37. Höhne GWH, Hemminger WF, Flammersheim H-J (2003) Differential scanning calorimetry. Springer Verlag Berlin Heidelberg New York, New York

38. Menczel JD, Judovits L, Prime RB, Bair HE, Reading M, Swier S (2009) In: Menczel JD, Prime RB (eds) Thermal analysis of polymers: fundamentals and applications. Willey, New Jersey, pp 7-240

39. Prasad A (1999) In: Mark JE (ed) Polymer data handbook. Oxford University Press, New York

40. Machado JC, Silva GG, Soares LS (2000) J Polym Sci B Polym Phys 38:1045-1052

41. Misheva M, Djourelov N, Dimitrova A, Zamfirova G (2000) Macromol Chem Phys 201:2348-2353

42. Chiappe C (2007) Monatsh Chem 138:1035-1043

43. Pádua AAH, Costa Gomes MF, Canongia Lopes JNA (2007) Acc Chem Res 40:1087-1096

44. Shimizu K, Costa Gomes MF, Pádua AAH, Rebelo LPN, Canongia Lopes JNA (2010) J Mol Struct THEOCHEM 946:70-76 